\title{
CANNABIS AND ALCOHOL IN ROAD TRAFFIC: AN OVERVIEW
}

\section{Marcinkova M, Straka L, Novomesky F.}

Department of Forensic Medicine and Medical Expertises, Jessenius Faculty of Medicine in Martin, Comenius University in Bratislava, and Martin University Hospital, Martin, Slovakia

\section{A b s tract}

Traffic medicine is an important part within the scope of concerns of forensic medicine. We are dealing with consequences of traffic accidents - fatal or survived - but this problem overlaps the borders of our specialization. Sustained injuries are the focus of various fields of medicine and in combination with alcohol and illicit drugs abuse this issue is growing. The following review has an ambition to bring more light into the problem concerning the effect of alcohol and cannabis (which is the most common illicit drug used worldwide) on driving abilities.

Key words: cannabis, alcohol, influence, road traffic, driving, detection.

\section{INTRODUCTION}

Road traffic accidents account for the great majority of injuries and incidents with fatal outcome, killing more than a million people annually and injuring 20-50 millions. Following the current trend, road traffic injuries are predicted to become the fifth-placed cause of death by 2030 (1). There are great regional differences in the death rates due to road traffic accidents worldwide - the rate is highest in the African region (24.2 per 100,000 population) and the lowest in Europe (10.3 per 100,000 population). The group of individuals aged 15 to 44 accounts for almost $60 \%$ of all traffic accident deaths (2).

Driving under the influence of alcohol or illicit drugs continues to be a concern in developed countries. Most commonly involved abused substance remains alcohol, followed by cannabis as a representative of illicit drugs (3). A study from Sweden monitoring 10 years of THC-positivity in drivers showed an increase of 11\% from 1995 (18\%) to 2004 (29\%) (4).

\section{Alcohol effect on driving}

Alcohol consumption has the biggest impact on visual system, when applied to driving abilities. Alcohol at blood concentrations greater than $0.5 \mathrm{~g} / \mathrm{kg}$ disrupts coordinated movement of eyes, leading to the characteristic horizontal gaze nystagmus (involuntary eyes jerking). It also worsens the capacity to see object localized further sharply and inhibits the ability to react quickly by eye moving to a desired object and to focus the image on the retina. The result is reaction time increase necessary to produce a response (5). Alcohol also reduces peripheral vision, resulting in so-called tunnel vision. Very well-known undesirable effect of alcohol consumption is double vision (diplopia). The affection of visual system occurs at any circumstances, however the absence of light intensifies the negative effects of alcohol on vision (5), posing a threat for night-out weekend drivers.

No less important is a detrimental effect of alcohol on the reaction time. Reaction time as part of the driving skill is a complex event composed of at least four components that last from approximately 2.5 to 3.5 seconds in an average person. The first component involves vision, the second component (identification) engages vision and the brain perception, the

Corresponding author: Lubomír Straka; e-mail: straka@unm.sk

(C) 2019 Marcinkova M et al.

This work is licensed under the Creative Commons Attribution-NonCommercial-NoDerivs 4.0 License (https://creativecommons.org/licenses/by-nc-nd/4.0/) 
third component (decision what to do) is primarily function of the brain. The final fourth component (reaction to a stimulus) involves all systems - vision, brain, nerves, and muscles (5). Blood alcohol concentration (BAC) ranging from 0.12 to $1.2 \mathrm{~g} / \mathrm{kg}$ increased simple reaction time by $5 \%$ to $17 \%(6,7,8,9)$, while blood levels from 0.5 to $1.5 \mathrm{~g} / \mathrm{kg}$ lenghtened the reaction time of subjects even more - from $42 \%$ to $82 \%(10,11,12)$. Alcohol doses of 1.0 to $1.2 \mathrm{~g} / \mathrm{kg}$ with alcohol levels averaging $1.1 \mathrm{~g} / \mathrm{kg}$, increased the reaction time in multitasking by more than $200 \%(13,14)$.

Other impairments that occur after alcohol and drug consumption and may lead to driving errors include alcohol-related disinhibition and increased risktaking, often leading to excessive speed or inconsiderate behavior, inability to perform more than one task at a time (impaired distributive attention), and increased sensitivity to full beams, especially in wet road conditions (15).

In relation to pharmacokinetics, alcohol-related driving errors occur more frequently during the absorption phase than at comparable blood alcohol concentration values during the elimination phase due to the accumulation effect. The effect of alcohol is determined not only interindividually (alcohol tolerance), but might easily be affected intraindividually as a result of tiredness, stress, illness, or medication (15).

\section{Cannabis effect on driving}

Cannabis consumption leads to a disturbance of optical and acoustic perception as well as to alterations of the ability to react and concentration. The effects of cannabis consumption with impact on traffic is deviation from traffic lanes and subsequent steering corrections (lane weaving), delayed reaction, failings of concentration and attentiveness, perception of irrelevant stimuli which may lead to subsequent disregard of traffic lights, and inadequate reactions to perceptions at the border of the visual field (for example pedestrians about to cross the road). In stressful situations elongated reaction times, accumulation of wrong or inadequate reactions, and disruptions of automatisms can be observed (16). Studies confirmed a dose-related risk between cannabis use and motor vehicles crashes involvement $(17,18)$. THC slows down the activity of the brain and other areas of the central nervous system while minor hallucinogenic effects can distort a person's perception of the environment. The effect of cannabis is highly individual and depends on ingestion route (after smoking the effects are experienced very quickly and may last up to 5-8 hours; after oral consumption the onset of effects can be delayed by about 60-90 minutes and can last up to 24 hours), dose, consumer's mental or emotional state, and physical health (16). After cannabis smoking THC concentration in blood increases rapidly, then decreases in the distribution phase, and during the elimination phase THC concentration declines more slowly (19). Many authors agree that performance impairment (in terms of executive function and motor control) is a function of the THC concentration in serum, so the risk of crash involvement is increased in a doserelated manner $(17,20,21)$. The lower and upper thresholds of a serum THC range for impairment were concluded from 2 to $5 \mu \mathrm{g} / 1$ (20). THC serum concentration of $7-10 \mu \mathrm{g} / 1$ is associated with impairment that is relevant for the ability to drive safely (22). With an average THC blood-to-plasma ratio of 0.7 this is equal to the concentration of 5-7 $\mu \mathrm{g} / 1$ in whole blood (19). German DRUID (acronym for Driving under the Influence of Drugs) research suggests that THC concentration of approximately $3.8 \mu \mathrm{g} / 1 \mathrm{in}$ blood causes driver impairment equivalent to a BAC of $0.5 \mathrm{~g} / 1$ (23). There is a chance for a person to be affected by cannabis use not only with high concentrations of THC in blood or plasma but also with concentrations less or equal to 1-2 $\mu \mathrm{g} / 1-$ the 'hangover' effects of cannabis which can last for several hours can also impair fitness to drive (16).

The drivers impaired by cannabis are often aware of their lack of abilities and employ compensational practices such as driving more slowly and increasing their following distance $(24,25,26)$. 


\section{Combination of alcohol and cannabis}

Even though the effects of alcohol and cannabis are different (5), based on the results of a recent study, cannabis-alcohol combination effects appear to be rather additive than synergistic (18). Concominant cannabis and alcohol consumption leads to an increase in unfavorable effects of cannabis (16). At a low dose of alcohol (producing BAC of 0.4-0.5 g/ kg) combined with a small dose of THC (1 $\mu \mathrm{g} / 1)$, driver visual search frequency at intersections was reduced and this effect was more pronounced in females (27). More severe impairment of driving behaviour was described after combining moderate doses of alcohol and marijuana. The mean reaction time increased from 4.65 seconds in unimpaired subjects to 6.33 seconds when the drivers were under the influence of both marijuana and alcohol (28). The drivers tested positive for both alcohol and cannabis had greater odds of making an error than the drivers positive for only one substance (3, 29, 30, 31).

\section{Profile of a risk driver}

The drivers tested positive for alcohol, THC, or both tended to be younger (aged 18-25), male sex, and had a poorer driving record compared to the drivers tested negative for both substances (3).

\section{Cannabis policy worldwide}

As the authors of the studies on effect of cannabis on driving skills processed data from various parts of the world, it is inevitable to bear in mind that laws concerning driving under the influence of cannabis vary greatly. There are three main types of law: zero tolerance, behavioural impairment, and non-zero (also called per se) (29). Any detection of THC or its metabolites in the driver's body is considered an offence in majority of European countries (zero tolerance). Any evidence of behavioural impairment detected by standardized field sobriety test (or DRE evaluation, see further) in defined as an offence in countries such as Hungary, Spain, and Canada. In countries with a specified threshold of THC or its metabolites in bodily fluid the presence of THC in concentration higher than the threshold is an offence. In Norway the legal limit is $1.3 \mu \mathrm{g} / 1 \mathrm{THC}$ in blood (32), in Denmark it is $1 \mu \mathrm{g} / 1$ (33). The combination of three beforementioned legislative approaches is called hybrid and is valid in Belgium, Germany, and Australia (29).

In USA cannabis has been legal in the following states: Alaska, California, Colorado, Maine, Massachusetts, Michigan, Nevada, Oregon, Vermont, and Washington (34). In addition, some local governments have established laws decriminalizing possession of cannabis, which has reduced the number of "simple possession" offenders sent to jail (35).

\section{Cannabis for medical purposes and its impact on driving}

For many drivers THC presence in blood may indicate a recreational use, but legalization of cannabis for therapeutic use is increasing around the world (36). Countries that have legalized the medical use of cannabis include Australia, Canada, Chile, Colombia, Finland, Germany, Greece, Israel, Italy, Norway, the Netherlands, Peru, Poland, and Thailand (35).

\section{Detection of alcohol and cannabis in bodily fluids}

A standard procedure for those who drive under the influence of psychoactive substances typically involves the collection of urine samples. Truth is that the results obtained from urine sample only provide retrospective information about past drug consumption (the last 2-3 days) and do not answer the question about the current effect of the drug on the person (37). Urine samples of occasional users are positive for THC metabolites from a few days until one week; however, urine samples of frequent users might be tested positive for many weeks (38). It is known that blood and oral fluid are better material to give the most accurate measurement of drugs currently active in the body (37). Otherwise urine 
has the advantage of being easy to collect in large volumes and is often the biological fluid of choice for laboratory-based drug-testing (32). There is a time-lag between the consumption of a drug and its appearance in urine, which makes the relationship between urinary drug concentrations and driving behaviour difficult to describe, particularly as the time-lag might be affected by many of factors (37). Over the last decade interest in the use of oral fluid for drug testing has been growing $(20,39)$. By comparision of findings in blood, urine, and oral fluid it was concluded that oral fluid is superior to urine in correlating with blood drug concentrations and driving behaviour (40). Even more, more drugs were confirmed in oral fluid than urine while testing (41). However, oral fluid is a specimen of choice for roadside testing according to literature (37), neither precise blood concentration of a drug nor the prediction of possible drug effects can be made (42). Average THC concentration in oral fluid is much higher than in blood; thus, different concentration cut-offs must be used (19). From the point of view of setting thresholds in a biological fluid, reference values (concentration versus effect ratios) are more readily available for blood (plasma or serum), which remains the matrix of choice (37). With regards to drug-driving legislation, whole blood is the currently preferred bodily fluid since it is well described in the scientific literature and is best related to behavioural effects on driving, remaining the 'gold standard' (43).

\section{Examination of a suspect}

Drug roadside screening seems to be the best prevention to the growth of the problem. Oral fluid is easy to collect, non-invasive, and reveals the recent cannabis intake (44). Dräger DrugTest ${ }^{\circledR}$ 5000, despite THC, provides screening of amphetamines, metamphetamines, cocaine, opiates, methadone, and benzodiazepines. The great advance of this system, consisting of test kit and analyzer, is its use on the spot with no need to send samples to the laboratory (45).

There is a massive research going on at the field of THC breathalyzers. The aim is to develop a device for roadside testing which would target the recent use of THC and would be non-invasive (in contrary to blood and urine sampling) (46). The combined THC and alcohol breath analyzer presents a higher level in roadside testing. Advantages of such analyzer should be the detection of recent marijuana use regardless of how it was consumed (smoking, eating) and taking two samples of exspired air - one for immediate results and one for future analysis (47).

The United States and Canada have implemented programs training the police officers to be Drug Recognition Experts (DREs). DRE is a police officer trained in the Drug Evaluation and Classification Program to recognize impairment in the drivers under the influence of alcohol and other drugs (48). When an alcohol or drug impairment is suspected by the police officer and the suspect's BAC is not consistent with the observed impairment, DRE evaluation is requested (49) and examined as soon as possible (50). The 12-steps-procedure consists of breath alcohol test, DRE interview with the arresting officer, preliminary examination and first pulse, eye examination (including horizontal and vertical gaze nystagmus and lack of convergence tests), divided attention psychophysical tests (e.g. Modified Romberg Balance or finger to nose, vital signs monitoring (blood pressure, body temperature, second pulse reading), darkroom examinations (pupil examination under three different lighting conditions), muscle tone examination, check for injection sites and third pulse reading, interview with the suspect, analysis and opinions of the evaluator, and toxicological examination as the last step. Detailed description of each step is documented in references $(48,50)$. The DRE evaluation includes four tests specifically designed to target impairment of divided attention, which is highly suspicious of cannabis consumption. The results of psychophysical tests and eye examination were concluded as the best indicators of cannabis impairment (49). 


\section{CONCLUSION}

Driving under the influence of alcohol and illicit drugs is a growing issue requiring multidisciplinary approach. As it relates to young people and traffic accidents may result in serious injuries or death (not mentioning the mental trauma), prevention is the problem to be solved, hopefully in near future. Toxicology testing provides answers to inevitable questions concerning the presence of the drug in deliquent's organism and its effect on his/her behaviour. Interpretation of the results of toxicology analyses at court has a great impact on penalty/sentence so it should be accentuated. General knowledge about commonly used illicit drugs and cooperation of specialists from various fields represents one of the keys for solving this complex issue.

\section{REFERENCES}

1. Saukko P, Knight B (eds). Knight's Forensic Pathology. 4th ed. Washington: CRC Press; 2015.

2. WHO Global Status Report on Road Safety 2013: Supporting a decade of action. Geneva: World Health Organization, Department of Violence and Injury Prevention and Disability.

3. Dubois S, Mullen N, Weaver B, Bédard M. The combined effects of alcohol and cannabis on driving: Impact on crash risk. Forensic Sci Int 2015; 248: 94-100.

4. Jones AW, Holmgren A, Kugelberg FC. Driving under the influence of cannabis: a 10-year study of age and gender differences in the concentrations of tetrahydrocannabinol in blood. Addiction 2008; 103: 452-461.

5. Garriott JC. Garriott's Medicolegal Aspects of Alcohol. 5th ed. Tuscon: Lawyers \& Judges Publishing Company, Inc.; 2008.

6. Blum B, Stern MH, Melville KI. A comparative evaluation of the actions of depressant and stimulant drugs on human performance. Psychofarmacologia 1964; 6: 173-177.

7. Boyd ES, Morken DA, Hodge HC. A psychomotor test to demonstrate a depressant action of alcohol. QJ Stud Alcohol 1962; 23: 34-39.

8. Buffard S. Study of the psychomotor reactions of 22 subjects after ingestion of a moderate quantity of alcohol. Ann Med Leg 1959; 39: 124-128.

9. Carlson AJ, Kleitman N, Muehlberger CW et al. Studies on the possible intoxicating action of 3,2 percent beer. Chicago: University of Chicago Press; 1934.

10. Huber O. Untersuchungen uber die Veranderung der Fahrtuchtigkeit von Kraftradfahrern nach massigem Alkoholgenuss. Dtsch Z Ges Gerichtl Med 1955; 44: 559-577.

11. Izard O, Saby G. Contribution a letude du comportement psychomoteur de 1 homme apres absorption de doses moyennes d alcool. Arch Mal Prof 1962; 23: 854-858.

12. Moureau P. Tendances de la legislation belge en ce qui concerne 1 intoxication alcoolique et les accidents de roulage. Rev Alcoolisme 1957; 4: 178-180.

13. Gruner O. Alkohol und Aufmerksamkeit. Ihre Bedeutung im motorisierten Verkehr. Dtsch Z Ges Gerichtl Med;1955; 44: 187-195.

14. Gruner O, Ptasnik H. The problem of the effects of levulose administration on loss of efficiency caused by alcoholism. Munch Med Wochenschr 1953; 95(35), 931-3.

15. Dettmeyer RB, Verhoff MA, Schütz HF. Forensic Medicine: Fundamentals and Perspectives. Berlin: Springer; 2014.

16. Madea B. Handbook of Forensic Medicine. 1st ed. Chichester: Wiley-Blackwell; 2014.

17. Ramaekers JG, Berghaus G, van Laar M, Drummer OH. Dose related risk of motor vehicle crashes after cannabis use. Drug Alcohol Depend 2004; 73: 109-119.

18. Hartman RL et al. Cannabis effects on driving lateral control with and without alcohol. Drug and Alcohol Dependence 2015; 154: 25-37.

19. Gjerde H, Mørland J. Letter to editor: Risk for involvement in road traffic crash during acute cannabis intoxication. Addiction 2016; 111: 1492-1495. 
20. Ramaekers JG, Kauert G, van Ruitenbeek P, Theunissen EL, Schneider E, Moeller MR. Highpotency marijuana impairs executive function and inhibitory motor control. Neuropsychopharmacology 2006; 31(10): 2296-303.

21. Downey LA, King R, Papafotiou K, Swann P, Ogden E, Boorman M, Stough C. The effects of cannabis and alcohol on simulated driving: influences ofdose and experience. Accid Anal Prev 2013; 50: 879-886.

22. Grotenhermen F, Leson G, Berghaus G, Drummer OH, Kruger HP, Longo M. et al. Developing limits for driving under cannabis. Addiction 2007; 102: 1910-7.

23. Berghaus G, Sticht G, Grellner E, Lenz D, Naumann T, Wiesenmüller S. Meta analysis of empirical studies concerning the effects of medicines and illegal drugs including pharmacokinetics on safe driving. DRUID Deliverable D 1.1.2b. Würzburg, Germany: University of Würzburg; 2010.

24. Kelly E, Darke S, Ross J. A review of drug use and driving: epidemiology, impairment, risk factors and risk perceptions. Drug Alcohol Rev 2004; 23: 319-344.

25. Berghaus G, Sheer N, Schmidt P. Effects of Cannabis on Psychomotor Skills, The University of Adelaide. NMHRC Road Accident Research Unit, 1995, p. 403.

26. Lenne MG, Dietze PM, Triggs TJ, Walmsley S, Murphy B, Redman JR. The effects of cannabis and alcohol on simulated arterial driving: Influences of driving experience and task demand. Accid Anal Prev 2010; 42: 859-866.

27. Lamers CTJ, Ramaekers JG. Visual search and urban city driving under the influence of marijuana and alcohol. Hum Psychopharmacol Clin Exp 2001; 16: 393-401.

28. Harris JS et al. Marijuana and alcohol combined severely impede driving performance. Ann Emerg Med 2000; 35: 398-399.

29. Watson TM, Mann RE. International approaches to driving under the influence of cannabis: A review of evidence on impact. Drug Alcohol Depend 2016; 169 148-155.

30. Robbe H. Marijuana's impairing effects on driving are moderate when taken alone but severe when combined with alcohol. Hum Psychopharmacol 1998; 13: S70-S78.

31. Ronen A, Chassidim HS, Gershon P, Parmet Y, Rabinovich A, Bar-Hamburger R, Cassuto Y, Shinar D. The effect of alcohol, THC and their combination on perceived effects, willingness to drive and performance ofdriving and non-driving tasks. Accid Anal Prev 2010; 42: 1855-1865.

32. Vindenes V, Jordbru D, Knapskog A, Kvan E, Mathisrud G, Slordal L, Morland J. Drugged driving arrests in Norway before and after the implementation of per se law. Forensic Sci Int 2012; 245: $171-177$.

33. Steentoft A, Simonsen KW, Linnet K. The frequency of drugs among Danish drivers before and after the introduction of fixed concentration limits. Traffic Inj Prev 2010; 11: 329-333.

34. Legality of cannabis by U.S. jurisdiction. Available online: https://en.wikipedia.org/wiki/Legality_of_cannabis_by_U.S._jurisdiction. Accessed 23.1.19

35. Legality of cannabis. Available online: https://en.wikipedia.org/wiki/Legality_of_cannabis . Accessed 23.1.19

36. Reinarman C, Nunberg H, Lanthier F, Heddleston T. Who are medical marijuana patients? Population characteristics from nine California assessment clinics. J Psychoact Drugs 2011; 43: 128-135.

37. Wolff K. Different Approaches to Setting Limits for Drugs and Alcohol Use When Driving. In: Wolff K, White J, Karch S (eds). The SAGE Handbook of Drug and Alcohol Studies. London: Sage 2017. p. $435-446$.

38. Cary PL. The marijuana detection window: determining the length of time cannabinoids will remain detectable in urine following smoking. Drug Court Practitioner 2006; 4: 1-15.

39. Drummer OH, Gerostamoulos J, Batziris H, Chu M, Caplehorn J, Robertson MD. The involvement of drugs in drivers of motor vehicles killed in Australian road traffic crashes. Accid Anal Prev 2004; 36: 239-48.

40. Toennes SW, Kauert GF, Steinmeyer S, Moeller MR. Driving under the influence of drugs: evaluation of analytical data of drugs in oral fluid, serum and urine, and correlation with impairment symptoms. Forensic Sci Int 2005; 152: 149-55. 
41. Logan BK, Mohr AL, Talpins SK. Detection and prevalence of drug use in arrested drivers using the Dräger Drug Test 5000 and Affiniton DrugWipe oral fluid drug screening devices. J Anal Toxicol 2014; 38(7): 444-50.

42. Gjerde H, Verstraete A. Can the prevalence of high blood drug concentrations in a population be estimated by analysing oral fluid? A study of tetrahydrocannabinol and amphetamine. Forensic Sci Int 2010; 195: 153-9.

43. Wille SM, Raes E, Lillsunde P, Gunnar T, Laloup M, Samyn N, Christophersen AS, Moeller MR, Hammer KP, Verstraete AG. Relationship between oral fluid and blood concentrations of drugs of abuse for drivers suspected of driving under the influence of drugs. Ther Drug Monit 2009; 31(4): 511-19.

44. Wille SM, Di Fazio V, Toennes SW, van Wel JH, Ramaekers JG, Samyn N. Evaluation of delta-9tetrahydrocannabinol detection using DrugWipe5Sscreening and oral fluid quantification after Quantisal collection for roadside drug detection via a controlled study with chronic cannabis users. Drug Test Anal 2004; 7: 178-186.

45. Dräger Products: Breath Alcohol and Drug Testing. Available online: https://www.draeger.com/ cs_cz/Applications/Products/Breath-Alcohol-and-Drug-Testing/Drug-Testing-Devices/DrugTest5000. Accessed 23.1.19

46. Marijuana breathalyzer. Available online: http://www.cannabixtechnologies.com/thc-breathalyzer.html\#. Accessed 18.1.19

47. Marijuana and alcohol breathalyzer. Available online: https://houndlabs.com/product-overview/. Accessed 18.1.19

48. International Association of Chiefs of Police: Drug Recognition Experts (DREs). Available online: https://www.theiacp.org/drug-recognition-experts-dres . Accessed 23.1.19

49. Hartman RL, Richman JE, Hayes CE, Huestis MA. Drug Recognition Expert (DRE) examination characteristics of cannabis impairment. Accid Anal Prev 2016; 92: 219-229.

50. Richman JE, McAndrew KG, Decker D, Mullaney SC. An evaluation of pupil size standards used by police officers for detecting drug impairment. Optometry 2004; 75(3): 175-182.

Received: January, 31, 2019

Accepted: April, 3, 2019 